\title{
AN INTEGRATED QUANTITATIVE RISK ANALYSIS METHOD FOR MAJOR CONSTRUCTION ACCIDENTS USING FUZZY CONCEPTS AND INFLUENCE DIAGRAM
}

Yong-Huang Lin Department of Construction Engineering, National Taiwan University of Science and Technology, Taipei, Taiwan, R.O.C.

Chen-Chung Lin Department of Construction Engineering, National Taiwan University of Science and Technology, Taipei, Taiwan, R.O.C. Institute of Occupational Safety and Health, Taipei County, Taiwan, R.O.C.

Yaw-Yauan Tyan

Department of Civil Engineering, China University of Technology, Taipei, Taiwan, R.O.C., yytyan@cute.edu.tw

Follow this and additional works at: https://jmstt.ntou.edu.tw/journal

Part of the Civil and Environmental Engineering Commons

\section{Recommended Citation}

Lin, Yong-Huang; Lin, Chen-Chung; and Tyan, Yaw-Yauan (2011) "AN INTEGRATED QUANTITATIVE RISK ANALYSIS METHOD FOR MAJOR CONSTRUCTION ACCIDENTS USING FUZZY CONCEPTS AND INFLUENCE DIAGRAM," Journal of Marine Science and Technology. Vol. 19: Iss. 4, Article 7.

DOI: $10.51400 / 2709-6998.2179$

Available at: https://jmstt.ntou.edu.tw/journal/vol19/iss4/7

This Research Article is brought to you for free and open access by Journal of Marine Science and Technology. It has been accepted for inclusion in Journal of Marine Science and Technology by an authorized editor of Journal of Marine Science and Technology. 


\title{
AN INTEGRATED QUANTITATIVE RISK ANALYSIS METHOD FOR MAJOR CONSTRUCTION ACCIDENTS USING FUZZY CONCEPTS AND INFLUENCE DIAGRAM
}

\author{
Yong-Huang Lin*, Chen-Chung Lin***, and Yaw-Yauan Tyan***
}

Key words: integrated quantitative risk analysis, construction accidents, fuzzy theory.

\begin{abstract}
The accident factor identification and risk assessment is an essential requirement for prevention of major construction accidents in the construction project process. An integrated quantitative risk assessment (IQRA) method has been proposed in this paper to overcome the problems of difficult to quantify accident probability for construction industry. The proposed approach employs influence diagram and fuzzy theory to estimate accident probability and to deal with the imprecision inherent to the process of subjective judgment. A case study that evaluates accident probability of diaphragm wall collapse is presented to illustrate the use of this methodology and to demonstrate its capability.
\end{abstract}

\section{INTRODUCTION}

The construction industry typically has a higher accident rate than other industries. Direct and indirect losses generated by major construction accidents reduce profits and can cause management crises. Such losses significantly impact construction business owners, workers, clients and the public. Developing accident prevention strategies and examining accident risks has become increasingly important [16]. As selection of personnel, material, machines and safety plan affects accident risk level and is closely related to total construction cost, an accident quantitative risk analysis (QRA)

Paper submitted 12/23/09; revised 03/08/10; accepted 04/04/10. Author for correspondence: Yaw-Yauan Tyan (e-mail: yytyan@cute.edu.tw).

*Department of Construction Engineering, National Taiwan University of Science and Technology, Taipei, Taiwan, R.O.C.

**Institute of Occupational Safety and Health, Taipei County, Taiwan, R.O.C.

***Department of Civil Engineering, China University of Technology, Taipei, Taiwan, R.O.C. method that considers construction conditions can be extremely useful in performing safety and economic analysis for planning prevention strategies of major accidents.

Working environments differ markedly between the construction and manufacturing industries. The working environment of the manufacturing industry is characterized by certain working areas and operational processes, and forms a relatively closed system in which the quantitative analysis of accident risk can depend on accident statistics and historical data. Conversely, individual construction project environments are usually outdoor, open and unique systems. Directors, operators, machinery, equipment and working environments change between projects. Therefore, gathering accident data from previous construction projects to predict quantitative risk for specific construction accidents in current projects is difficult. Additionally, accident causal factors (e.g., personnel, machinery, materials, construction methods, geography, geology, and weather conditions) are numerous, complex and highly interdependent. The QRA technique commonly used in the manufacturing industry (e.g., fault tree analysis and event tree analysis.) is unsuitable for construction accident analysis. The main goal of this study is to create an accident IQRA tool integrating accident causation theory, influence diagrams and fuzzy theory for use in safety analysis, influence factors analysis and economic analysis for accident prevention strategy planning.

This study highly focuses on developing a IQRA methodology that can quantify the probability of a specific construction accident. The QRA methodology can be used to perform safety and economic analysis for optimizing accident prevention strategy. For ambiguous and complex construction accident situations, it is often difficult to collect useful historic data for QRA of construction accidents. This study creates a hierarchical fuzzy system that applies accident causation theory, influence diagrams and fuzzy theory for analyzing accident causal relationships and quantifying accident probability. Experts can assist in developing accident factor influence diagram, assessing the conditions of accident causal factors, 
developing fuzzy rule bases of a hierarchical fuzzy system and predicting accident costs.

\section{LITERATURE REVIEW}

Few studies have applied quantitative analysis to assess the risk of a specific accident in construction operations. Ayyub and Haldar [2] used fuzzy theory to assess the quantitative risk of failure of construction alternatives, and considered worker skill, supervisor experience and falsework condition as the three principal factors affecting construction operation safety, for selecting the most desirable construction strategy. Lee and Halpin [17] used the same method and three accident causal factors to predict the probability of accidents in utility-trenching operations via fuzzy relations and fuzzy probability [37] Fuzzy probability was finally normalized to a mean value to perform sensitivity analysis for the various factors. These methods focus on risk causal factor selection and use selected fuzzy membership function of probability to forecast the probability of failure or accidents in operations. In practice, the quantitative risk analysis involved in specific accidents is very useful in the safety and economic analysis of accident prevention strategies.

Besides these construction accident risk studies, Tanaka et al. [30] proposed using fuzzy sets defined in a probability space to determine system failure in a fault tree model according to the extension principal. Singer [23] applied a fuzzy set approach to fault tree and reliability analysis, and discussed the tolerances of the probability values of hazard events in complex systems. Suresh et al. [26] presented a fuzzy methodology for ranking system components or basic events based on their contribution to the top event failure probability and the uncertainty of the top event. Tah and Carr $[28,29]$ applied fuzzy logic and a hierarchical risk breakdown structure to develop a formal model for construction project QRA. Cho et al. [5] proposed a fuzzy-based uncertainty model for risk assessment for considering the uncertainty range that represented the degree of uncertainty of both probabilistic parameter estimates and subjective judgments. Choi et al. [6] applied this model to design a software for risk assessment of underground construction projects. Etienne [10] enabled a procedure to import arguments from post-accident studies and to combine them with empirical data on normal operational organizations in order to produce relative measures of reliability. Dağdeviren et al. [9] proposed a fuzzy analytic network process model to identify faulty behavior risk in work system.

Many studies have discussed accident causation theories for various industries and are important for risk analysis. During the 1930s, Heinrich [11] first proposed the Domino Theory and considered five factors in accident sequences. The accident sequence is that human behavior deficiencies, preceded and influenced by social and environmental factors, might lead to an unsafe state, accident, and injury. Unsafe states are described as "unsafe acts and mechanical hazards" that are central in the accident sequence and are key to re- moving the effectiveness of preceding factors. Weaver [32] used "unsafe act and/or condition" as the central domino for modifying the domino theory of Heinrich. Unsafe acts and conditions are generally traceable to poor management policies and decisions, in addition to personal and environmental factors [34]. Nishishima [19] introduced a fishbone model to describe the accident causation process, in which four related factors generate unsafe states and unsafe behaviors. These factors include human, equipment, work, and management. Bellamy and Geyer [3] proposed a sociotechnical pyramid model of accident causation, which consists of five causal factors: engineering reliability, operator reliability, communication and feedback control, organization and management, and psychological climate.

In the construction industry, Hinze [12] proposed a distraction theory based on the assumption that accident risk may result from work distractions caused by physical hazards or mental diversions. Suraji et al. [25] developed a constraint-response model that describes the constraints and responses experienced by parties involved in project conception, design, and construction, which may affect accident causation. This model considers both proximal and distal factors (e.g., operative factors, site environment and work systems, and project management and organizational issues). Choudhry and Fang [7] identified some influence factors (e.g., safety procedure, experience, and education) on the safety behavior of construction workers.

The literature review reaches the following conclusions:

1. Previous discussions of construction accident risk focused on failure or accidents in operations using a probabilistic perspective. Few studies have examined specific accident risks by adopting quantitative perspectives. In practice, the quantitative analysis involved in specific accidents is very useful in the safety and economic analysis of accident prevention strategies.

2. For construction projects that have open, unique and complex systems, accumulating suitable historical data to conduct accident QRA becomes difficult. Previous studies indicate that expert judgment and fuzzy theory can be applied in risk analysis.

3. General QRA methods such as fault tree analysis (FTA) or event tree analysis (ETA) must precisely analyze the causal relationships involved in risk events; however, because of the openness, uniqueness and complexity of construction projects, establishing analytical causal relationships for accident scenarios is difficult. Some studies have applied fuzzy relations to establish causal relationships for accident risk analysis considering few influence factors.

4. Most accident causation theories share the common concept that direct and proximal causal factors are unsafe acts and conditions, and can be further analyzed as resulting from three primary failures, namely poor conditions of humans (e.g., skill and experience of labor and director), engineering (e.g., equipment, material, machine, working 


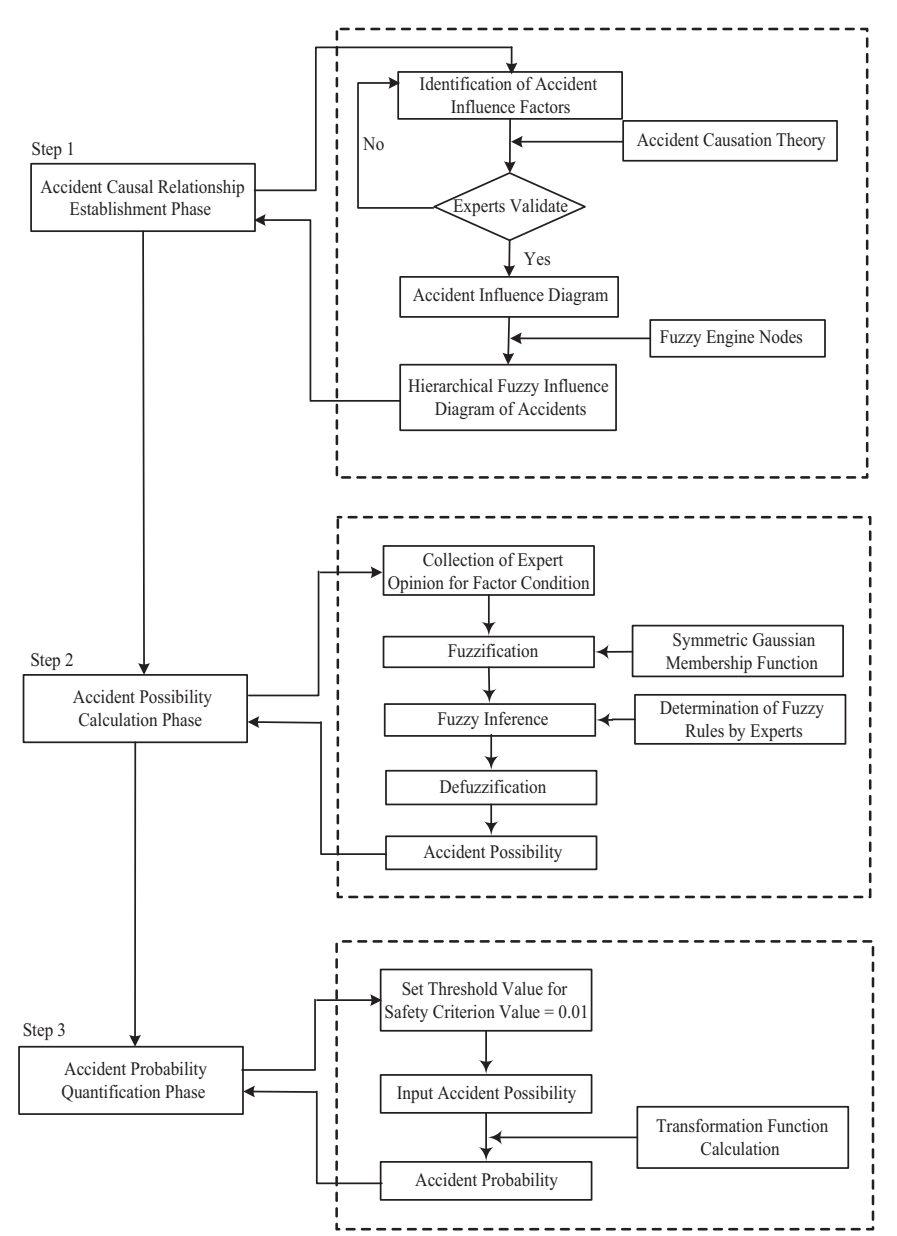

Fig. 1. The main steps of quantitative risk analysis for accident probability.

method), and working environment (e.g., site condition, weather). Therefore, the measurement and improvement of the safety performances of these causal factors are essential to risk analysis and accident prevention on working sites.

\section{METHODOLOGY}

This study proposes a quantitative analysis methodology focused on major accident probability to perform risk and safety analysis for preventing construction accidents. This methodology combines accident causation theory, influence diagrams and fuzzy theory to quantify accident probability based on expert judgment. Fig. 1 shows the main steps of quantitative risk analysis for accident probability.

\section{Establishment of Accident Causal Relationships Using Influence Diagrams and Fuzzy Systems}

Based on the accident causation, this study utilizes influence diagrams and fuzzy theory to develop a hierarchical structure of accident causal relationships for further risk assessment. The influence diagram, proposed by Howard and Matheson [13], is applied early for strategy analysis and mainly indicates the relationships among related influential factors. Ashley and Bonner [1] used influence diagrams to illustrate the status and interactive influential relationships of risk factors for construction project risk analysis. Afterwards, this tool is applied to risk analysis, decision analysis, and probabilistic inference. This study utilizes influence diagrams to organize accident causal factors to describe the possibility of a specific accident that may occur during construction. In this study, the possibility is the subjective measure of likelihood defined in the fuzzy concept for further quantification of accident probability. Based on accident causation theory, the direct influence factors on accident possibility are the possibility of on-site unsafe acts and conditions. These two factors are closely related to the states of on-site working conditions and work personnel. That is, the worse the states of working conditions and work personnel, the higher the possibility of unsafe conditions and acts and the higher the relative accident possibility. Working conditions and working personnel can be further divided into many on-site and human factors. For example, engineering and environmental states form the state of working conditions, and the states of operators and directors, two key parties involved in construction sites, form the state of work personnel. These factors can be hierarchically divided into many detailed factors (e.g., performances of temporary structures, machines and materials, conditions of site geology, geography and weather, skills and experience of operators, and directors, etc.) based on expert judgments and project attributes. The upside of Fig. 2 shows an example of the influence diagram organizing accident and causal factors. These factors are variables whose states influence subsequent accidents and are easily expressed by linguistic terms such as very good, good, medium, and so on. Fuzzy theory thus can play a fundamental role in formulating quantitative linguistic variables by fuzzy sets, and can also deduce the relationships among causal factors using fuzzy logic. This study combines influence diagrams and fuzzy theory to develop the influence diagram of accident possibility using the hierarchical fuzzy system, called the hierarchical fuzzy influence diagram (HFID) here. The downside of Fig. 2 displays the example of a HFID by adding fuzzy engine nodes following each causal factor which is impacted by other factors. HFID helps in analytically developing the hierarchical structure of accident causal relationships based on accident causation theory and solves the rule-explosion problem (i.e., the number of rules increases exponentially with the number of input variables to the fuzzy controller) of a multi-variable (i.e. high-dimensional) fuzzy system using a hierarchical fuzzy system comprising low-dimension fuzzy systems. Previous studies have demonstrated that the number of rules in the hierarchical fuzzy system increases linearly with the number of input variables, and that the hierarchical fuzzy system can approximate any nonlinear function on a compact set to arbitrary accuracy [31]. HFID thus forms the basis of the quantification of accident probability by operations of the hierarchical fuzzy system in this study. 


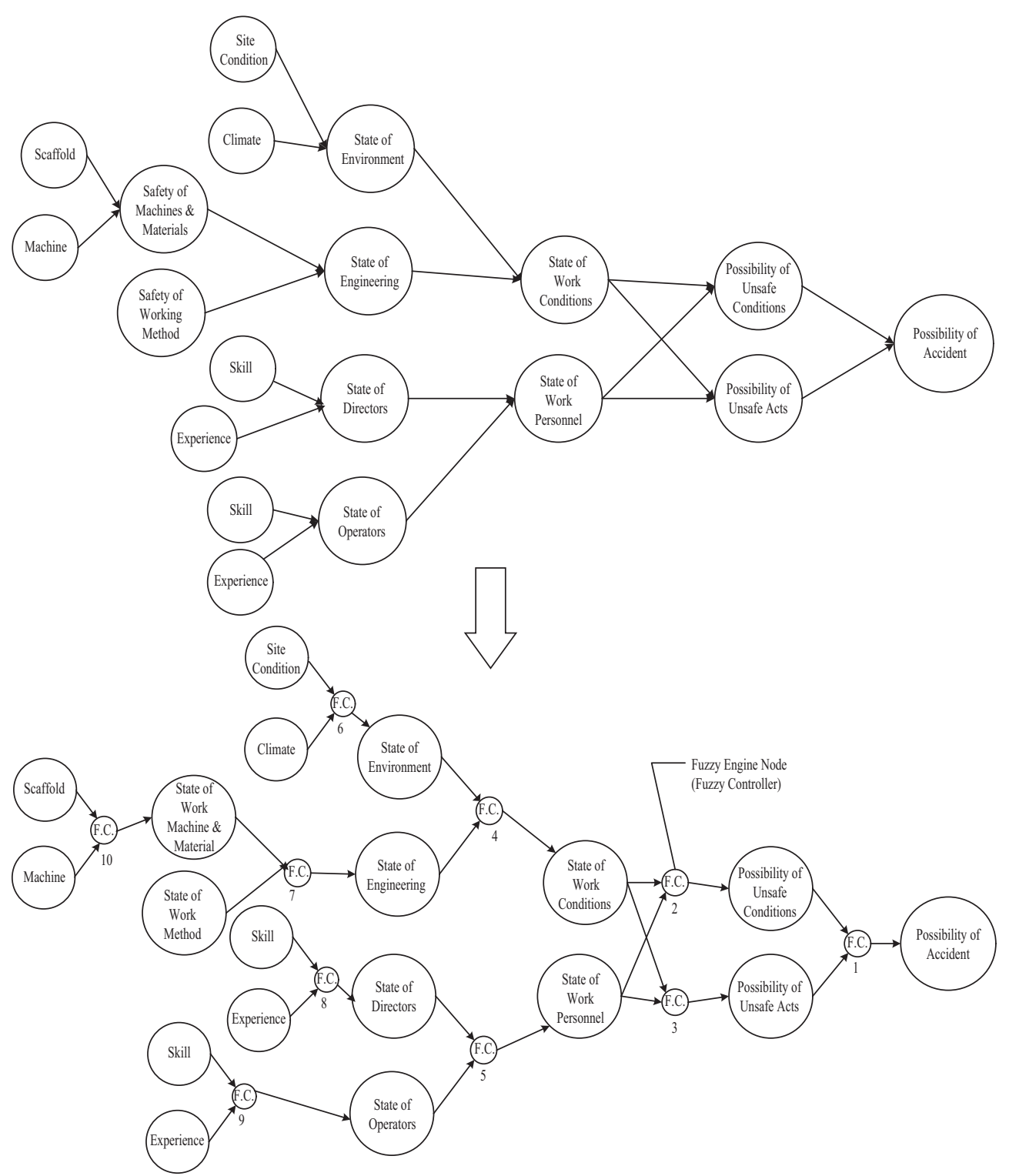

Fig. 2. Inference of accident possibility using hierarchical fuzzy influence diagram. (The upside of Fig. 2 shows an example of the influence diagram organizing accident and causal factors. The downside of Fig. 2 displays the example of a HFID by adding fuzzy engine nodes following each causal factor which is impacted by other factors.)

\section{Calculation of Accident Possibility by Hierarchical Fuzzy Systems}

The concepts of fuzzy theory and fuzzy systems were proposed by Zadeh [35, 36]. Generally, a fuzzy system is any system whose variables (or at least some of them) range over states that are fuzzy sets. Fuzzy sets here are fuzzy numbers, and the associated variables are linguistic variables. Representing states of variables using fuzzy sets is a way of quantifying the variables. The most successful area of application of fuzzy systems has undoubtedly been the area of fuzzy control; this area is used to evaluate accident likelihood for purposes of safety and economic analysis in developing accident control strategies in this study. A general fuzzy controller consists of four modules: a fuzzy rule base, a fuzzy inference engine, and fuzzification/defuzzification modules. Fig. 3 presents a general fuzzy controller with two-input variables and one-output variable.

Although fuzzy control techniques have been successfully applied to various problems, applications are usually limited to systems with few input variables. A fundamental limitation of standard fuzzy controllers is that the number of fuzzy rules increases exponentially with the number of input variables. This phenomenon was called by Bellman [4] the "curse of dimensionality". The rule base rapidly overloads the memory and makes the fuzzy controller unimplementable. For example, with 8 input variables and 7 fuzzy sets defined for each variable, the number of fuzzy rules is $7^{8}=5764801$. This problem can be solved by using hierarchical fuzzy systems. If 


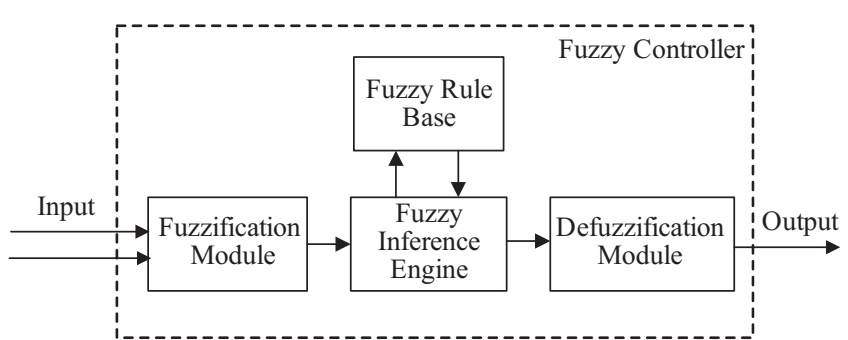

Fig. 3. Fuzzy controller with two-input variables, one-output variables and four modules (a fuzzy rule base, a fuzzy inference engine, fuzzification, and defuzzification modules).

the 8-variable fuzzy system is reduced into a hierarchical fuzzy system comprising ten hierarchically connected low-dimensional fuzzy systems as shown in Fig. 2, the number of fuzzy rules reduces to $10 \times 7^{2}=490$. Previous studies have demonstrated that hierarchical fuzzy systems with decomposed low-dimensional fuzzy systems can approximate any nonlinear function to arbitrary accuracy $[15,31]$. Hierarchical fuzzy systems can be applied to more complex systems, such as the systems of accident causal relationships in this study.

A hierarchical fuzzy system operates by repeating a cycle of four-step operations (shown as Fig. 3) in each fuzzy controller within the system from bottom to top. The input and output variables of each fuzzy controller are all linguistic variables and the state of each variable is a linguistic expression of each expert opinion from a macroscopic point of view. One advantage of using linguistic variables is that such expressions are more intuitive and make it easier for experts to give their opinions in ambiguous and complex situations in which numerical estimations are hard to obtain. According to Wickens [33], the typical estimate of human working memory capacity is $7 \pm 2$ chunks, meaning humans can effectively make 5-9 comparisons at a time. This study assesses the state of each input factor (i.e. linguistic variable) using seven linguistic values \{"Very High (Good)", "High (Good)", "Fairly High (Good)", " Medium", "Fairly Low (Bad)", "Low (Bad)", "Very Low (Bad)" \}:

$$
\begin{aligned}
& \text { Very High }(\mathrm{Good})=\mathrm{VH} / \mathrm{VG}=u(x, 0.085,1) \\
& \text { High }(\mathrm{Good})=\mathrm{H} / \mathrm{G}=u(x, 0.085,5 / 6), \\
& \text { Fairly High }(\mathrm{Good})=\mathrm{FH} / \mathrm{FG}=u(x, 0.085,4 / 6) \\
& \text { Medium }=\mathrm{M}=u(x, 0.085,3 / 6), \\
& \text { Fairly Low }(\mathrm{Bad})=\mathrm{FL} / \mathrm{FB}=u(x, 0.085,2 / 6) ; \\
& \text { Low }(\mathrm{Bad})=\mathrm{L} / \mathrm{B}=u(x, 0.085,1 / 6), \\
& \text { Very Low }(\mathrm{Bad})=\mathrm{VL} / \mathrm{VB}=u(x, 0.085,0) . \\
& \text { where } u(x, \sigma, c)=e^{\frac{-(x-c)^{2}}{2 \sigma^{2}}}
\end{aligned}
$$

The symmetric Gaussian function, shown as Eq. (1), is selected as the membership function of each input variable, and

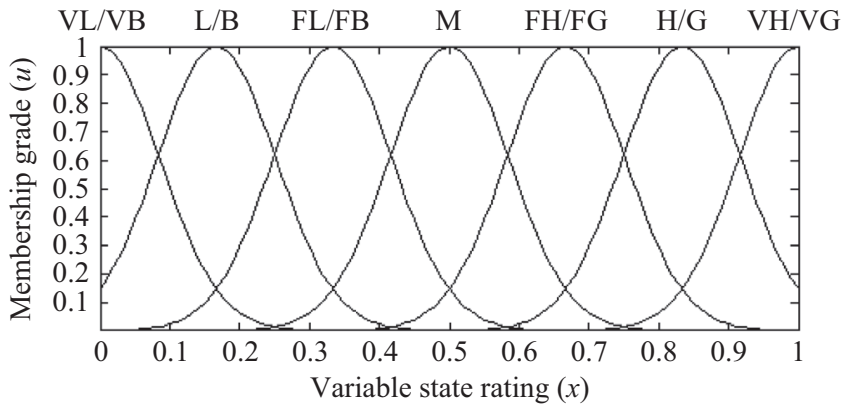

Fig. 4. Gaussian membership functions of linguistic variables (where $\left.u(x, 0.085, c)=e^{\frac{-(x-c)^{2}}{2 \sigma^{2}}}, c=\{0,1 / 6,2 / 6,3 / 6,4 / 6,5 / 6,1\}\right)$.

forms the fuzzy sets shown in Fig. 4. First, measurements are taken of all input variables representing relevant states of causal factors. Next, these measurements are converted into appropriate fuzzy sets to express measurement uncertainty. This step is called fuzzification.

The fuzzified measurements are then used by the inference engine to evaluate whether each rule stored in the fuzzy rule base is triggered. Each rule is a logical inference regarding the states of input and output variables. Fig. 5 illustrates the fuzzy rule base in matrix form. The fuzzy logic if-then rule performs approximate reasoning using imprecise or vague dependencies and commands [37], in which the antecedent and consequent are propositions containing linguistic variables, and has the following form:

$$
\text { If } X_{1} \text { is } A_{i 1} \ldots \text { and } X_{n} \text { is } A_{\text {in }} \text { then } Y \text { is } B_{i}, i=1, \ldots, m
$$

where $n=$ number of input variables $X=\left\{X_{1}, \ldots, X_{n}\right\}$ and $m=$ number of rules; $A i j$ and $B i$ are linguistic values of $X$ and $Y$, respectively. In Fig. 5, $n=2, m=7 \times 7=49$.

Next, the fuzzy inference engine calculates the rule strength or level of firing of the antecedents (inputs) "If $X_{1}$ is $A_{i 1} \ldots$ and $X_{n}$ is $A_{\text {in }}$ " for aggregating all the rules triggered to produce one output membership function. The most commonly seen fuzzy inference methods are those of Mamdani [18] and Sugeno [24]. The main difference between the Mamdani and Sugeno methods of fuzzy inference is that in the Sugeno method the output membership functions must be linear or constant. Because of the linear dependence of each rule on the system input variables, the Sugeno method is ideally suited to the task of smoothly interpolating the linear gains that would be applied across the input space. The Sugeno system is suited for modeling nonlinear systems by interpolating multiple linear models. This study selects the Sugeno method as the fuzzy inference engine, and the membership functions of the seven linguistic values of each output variable are a set of constants (i.e. $\mathrm{B}=\{$ "VH/VG", "H/G", "FH/FG", "M", "FL/FB", "L/B", "VL/VB" $\}=\{1,5 / 6,4 / 6,3 / 6,2 / 6,1 / 6,0\})$.

The rule strength can be derived using the composition conjunction, as follows: 


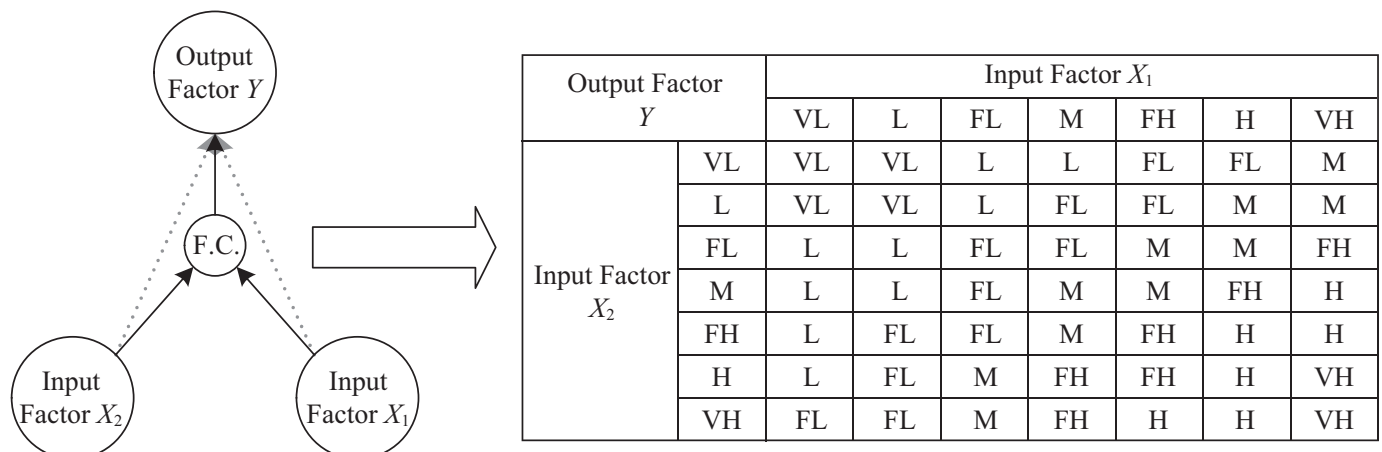

Fig. 5. Illustration of the fuzzy rule base in matrix form based on a fuzzy controller with two-input variables and one-output variables.

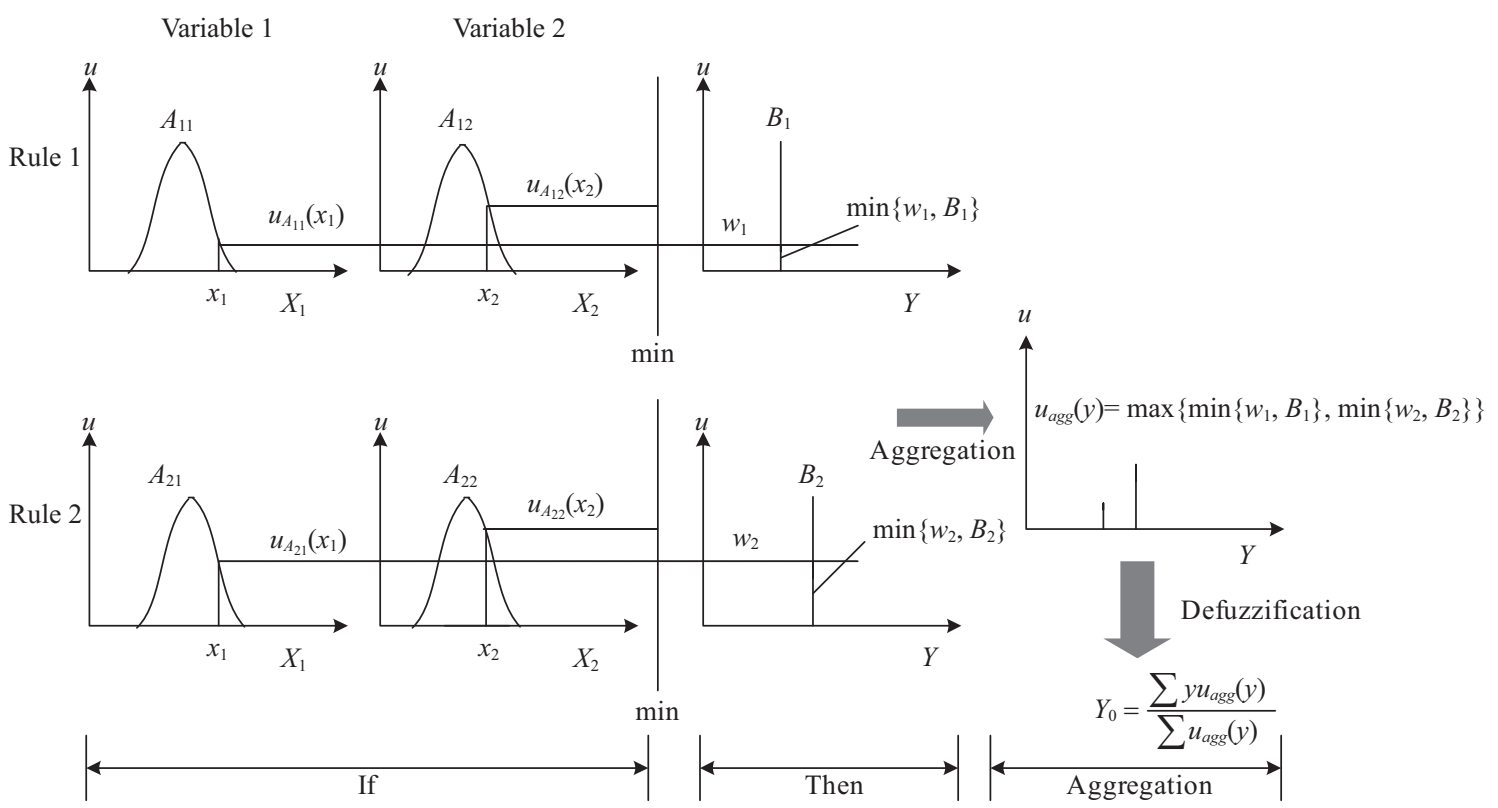

Fig. 6. Operation of the Sugeno-type fuzzy inference engine and the defuzzification using the center of gravity method (COG).

$$
w_{i}=\min \left[u_{A i 1}\left(x_{1}\right), u_{A i 2}\left(x_{2}\right), \ldots, u_{A i n}\left(x_{n}\right)\right]
$$

The Sugeno-type fuzzy inference engine finally generates one output associated with membership function $u_{\text {agg }}(y)$ using a conjunction operation on the rule strength $\left(w_{\mathrm{i}}\right)$ and the constant for the linguistic value of the consequent.

$u_{\text {agg }}(y)=\max \left\{\min \left[w_{1}, B_{1}\right], \min \left[w_{2}, B_{2}\right], \ldots, \min \left[w_{m}, B_{m}\right]\right\}$

The output $u_{\text {agg }}(y)$ of the Sugeno-type fuzzy inference engine has to be expressed by a crisp value for the next operation of the fuzzy controller. This study adopts the center of gravity method (COG) for the defuzzification:

$$
Y_{0}=\frac{\sum_{i=1}^{m} y_{i} u_{\text {agg }}\left(y_{i}\right)}{\sum_{i=1}^{m} u_{a g g}\left(y_{i}\right)}
$$

Fig. 6 illustrates the operation of the Sugen-type fuzzy inference engine and defuzzification method.

To more reliably assess the accident possibility with linguistic variables, it is necessary to aggregate the opinions of multiple experts. Numerous methods are available for aggregating expert opinions, such as voting, arithmetic averaging, fuzzy preference relations, the max-min Delphi method, and the fuzzy Delphi method. However, no firm theoretical guidance can be provided for choosing the most suitable method [14]. The arithmetic averaging operation satisfies two characteristics of rational combination [8]: (a) a small variation in any possibility distribution does not noticeably impact the combined possibility distribution; and (b) when experts are equally weighted it can also include weights that indicate the relative importance of different experts. The arithmetic averaging operation is also the most commonly used. Thus, arithmetic averaging is used to aggregate expert judgments regarding the input variables and fuzzy rules. That is, the weight of the estimation of each expert regarding linguistic 


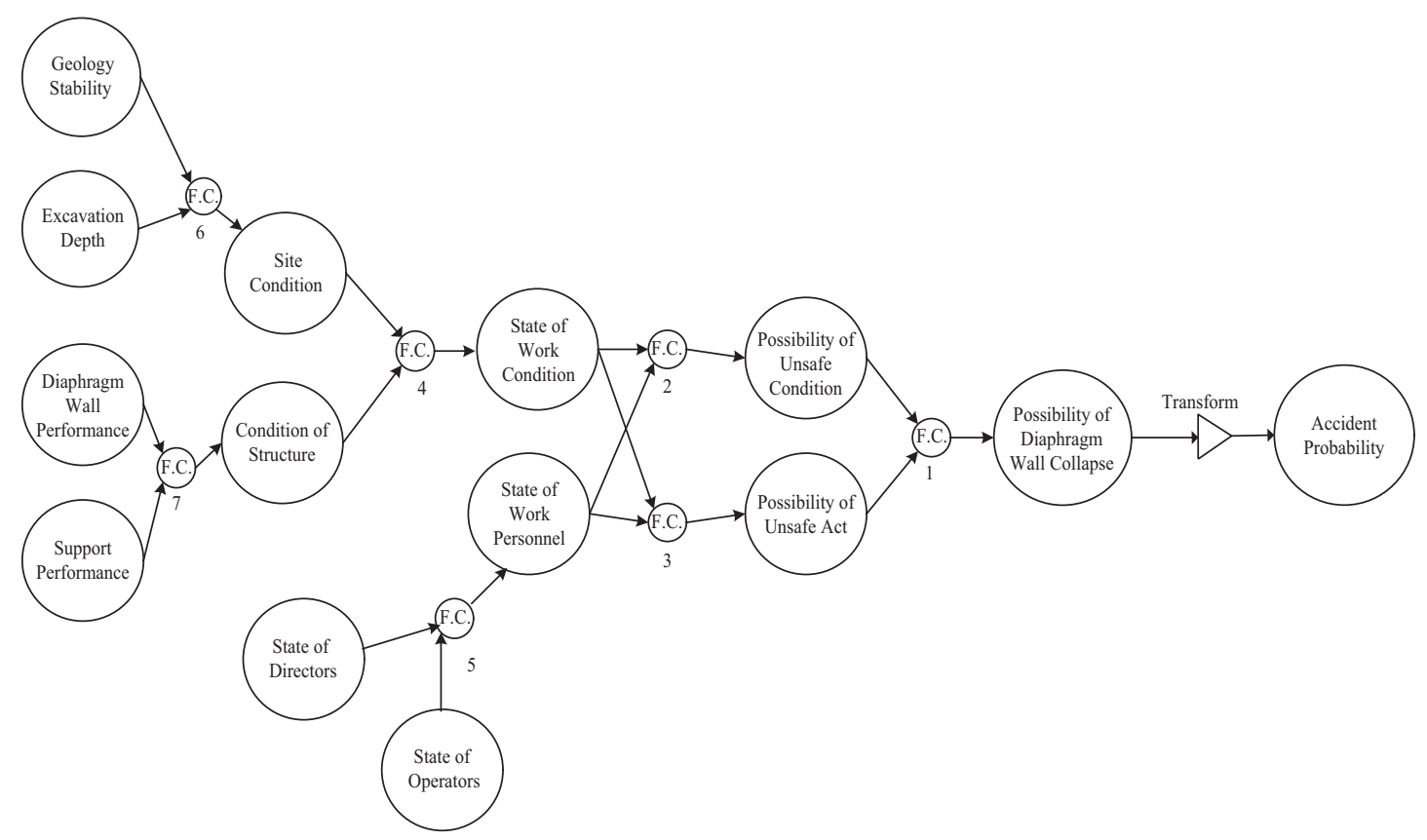

Fig. 7. Accident probability influence diagram of diaphragm wall collapse used for case study in this paper.

value and fuzzy rules equals $1 / p$, where $p=$ the number of experts involved in the assessment.

\section{Quantification of Accident Probability}

To perform quantitative safety and economic analysis of accident prevention strategies, a transformation is required to convert the subjective accident possibility into the relatively objective accident probability. Onisawa [20-22] has proposed a function which can be used to convert these two measurements. This function is derived by satisfying certain properties such as the proportionality of human sensation to the logarithmic value of a physical quantity [14]. The accident probability can then be obtained from the accident possibility, as follows:

$$
\begin{aligned}
& P b=1 / 10^{\mathrm{M}}, \text { when } P s \neq 0, \\
& P b=0, \text { when } P s=0, \\
& M=(1 / P s-1)^{1 / 3} \times \log (1 / P s c),
\end{aligned}
$$

where $P b \equiv$ failure probability, $P s \equiv$ failure possibility, $P s c \equiv$ safety criterion.

Safety criterion denotes the probability that can be used as a standard to assess operating safety via comparison with the predictive accident probability. If the accident probability exceeds the safety criterion, the on-site operation is less safe, and vice versa. Safety criterion value is generally an experience value based on historic data, expert judgment and enterprise risk taking ability. Swain and Guttmann [27] suggested that the routine error rate is $10^{-2}-10^{-3}$ and the lower bound error rate is $5 \times 10^{-5}$. Based on the high error rate and low reliability of construction systems, this study assigns $10^{-2}$ as the safety criterion (Psc).

\section{CASE STUDY}

A practical case study is used to illustrate the application of the accident IQRA tool. The case involves considering the collapse risk of diaphragm walls during an underground deep excavation operation. The collapse accident may lead to catastrophic consequences to construction companies; hence quantitative analysis of accident probability is very important for further safety analysis, economic analysis and decisionmaking related to accident prevention strategies.

The first step of performing IQRA is to use the proposed accident probability quantification methodology. Four experts were consulted for modeling accident causal relationships. Based on the accident scenario and the practical experiences of experts, six principal causal factors were proposed as bottom factors for further developing an accident HFID. Fig. 7 shows an integrated accident risk influence diagram based on accident causation theory and the application of the hierarchical fuzzy system.

Each expert must provide a fuzzy rule base for each fuzzy controller according to the accident risk influence diagram shown in Fig. 7. The diagram contains seven fuzzy controllers and Table 1 shows the 6th fuzzy controller's rule base provided by one of four experts. The final fuzzy rule base associated with each fuzzy controller is an aggregation of four expert rule bases where the weight of each rule equals $1 / 4$.

Table 2 lists four expert judgments regarding the linguistic values of six accident causal factors. Each representative value is defuzzified from a fuzzy set obtained by averaging 
Table 1. Example of a fuzzy rule base provided by one of four experts represents the 6th controller shown in Fig. 7 with two input variables (geology stability and excavation depth) and one output variable (site condition).

\begin{tabular}{|c|c|c|c|c|c|c|c|c|}
\hline \multirow{2}{*}{\multicolumn{2}{|c|}{ Site condition }} & \multicolumn{7}{|c|}{ Geology stability } \\
\hline & & VB & $\mathrm{B}$ & FB & $\mathrm{M}$ & $\mathrm{FG}$ & $\mathrm{G}$ & VG \\
\hline \multirow{7}{*}{ Excavation depth } & VL & FB & $\mathrm{M}$ & $\mathrm{FG}$ & $\mathrm{G}$ & $\mathrm{G}$ & $\mathrm{VG}$ & $\mathrm{VG}$ \\
\hline & $\mathrm{L}$ & FB & FB & $\mathrm{M}$ & $\mathrm{FG}$ & $\mathrm{G}$ & $\mathrm{G}$ & $\mathrm{VG}$ \\
\hline & FL & $\mathrm{B}$ & FB & $\mathrm{M}$ & $\mathrm{FG}$ & $\mathrm{FG}$ & $\mathrm{G}$ & $\mathrm{G}$ \\
\hline & $\mathrm{M}$ & $\mathrm{B}$ & $\mathrm{B}$ & FB & $\mathrm{M}$ & FG & FG & $\mathrm{G}$ \\
\hline & $\mathrm{FH}$ & $\mathrm{B}$ & $\mathrm{B}$ & $\mathrm{B}$ & FB & $\mathrm{M}$ & $\mathrm{M}$ & FG \\
\hline & $\mathrm{H}$ & $\mathrm{VB}$ & VB & $\mathrm{B}$ & FB & FB & FB & $\mathrm{M}$ \\
\hline & $\mathrm{VH}$ & VB & VB & VB & $\mathrm{B}$ & $\mathrm{B}$ & $\mathrm{B}$ & FB \\
\hline
\end{tabular}

Table 2. States of six accident causal factors assessed by four experts and their representative values defuzzified from a fuzzy set obtained by averaging four experts' membership functions.

\begin{tabular}{lccccc}
\hline Accident causal factor & Expert A & Expert B & Expert C & Expert D & Representative value \\
\hline Geology stability & B & FB & FB & M & 0.333 \\
\hline Excavation depth & H & FH & H & FH & 0.750 \\
\hline Diaphragm wall performance & M & M & FG & M & 0.542 \\
\hline Support performance & FG & G & G & G & 0.792 \\
\hline State of directors & FG & G & FG & FG & 0.708 \\
\hline State of operators & FG & FG & FG & M & 0.625 \\
\hline
\end{tabular}

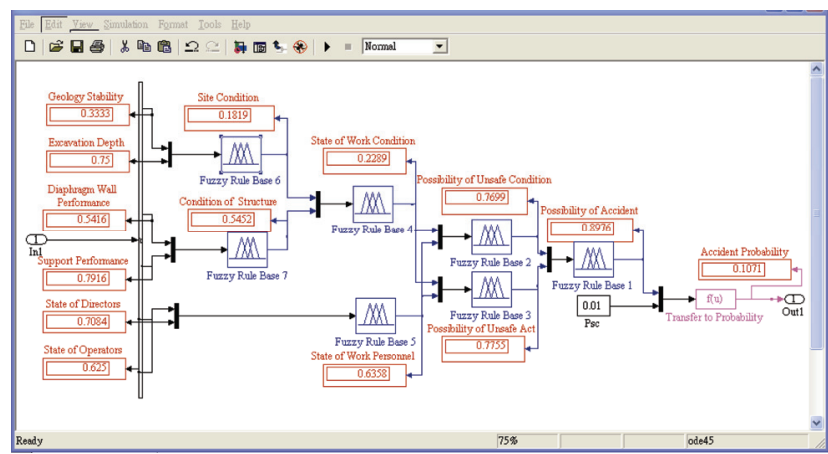

Fig. 8. Operation of the hierarchical fuzzy system designed using the accident hierarchical fuzzy influence diagram shown in Fig. 7.

these membership functions for expressing the linguistic values of the judgments of four experts on the state of each input variable. Using these representative values as input, hierarchical fuzzy system operations can be initiated to calculate accident probability.

To obtain the expected value of quantitative accident probability, this study designed a graphical user interface program to efficiently calculate the hierarchical fuzzy system using Fuzzy Logic Toolbox and Simulink Toolbox built in MATLAB, a numerical computing environment and programming language created by MathWorks, Inc. Fig. 8 illustrates the inner operations of the hierarchical fuzzy system designed using the accident HFID shown in Fig. 7. In this example program calculation is used to obtain the final accident probability expected value of 0.1071 .
Based on the above analysis, the accident probability expected value of 0.1071 exceeds the value of safety criterion, which is assigned a value of 0.01 in this study, implying that the current condition of construction operation in the example presented here is unsafe and an unacceptable risk of collapse exists. Using this tool to conduct follow-up safety analysis, influence factors analysis and economic analysis will be necessary and applicable.

\section{CONCLUSIONS}

This study combines fuzzy theory, HFID and probability-possibility convertible functions to generate a novel quantitative approach based on expert judgment. The construction industry is a high-risk business in which major accidents can cause large direct and indirect losses. Besides preventing common injuries (e.g., falls and electrical shocks) to general laborers, it is extremely important to prevent major construction accidents (e.g. collapses). Historically, few risk assessments focused on QRA of accident probability. Enterprises can use this developed tool to conduct accident IQRA, influence factors analysis, safety analysis and economic analysis.

As construction sites are typically open outdoor systems, each construction project is unique. Consequently, it is extremely difficult to use accident data from previous construction projects to predict the quantitative risk for a specific accident. Furthermore, the relationships among accident causal factors in the construction industry are extremely complex and fuzzy; that is, it is difficult to use general QRA methods, such as fault tree analysis and event tree analysis, to define rela- 
tively analytical causal relationship. This study adopts an overall perspective and emphasizes that the application of the qualitative accident causation model and subjective expert judgment can simplify hard-to-quantify problems involved in construction accident risk assessment.

This study utilizes accident causation theory to establish a HFID for accident risk analysis. The proposed method can conduct risk assessment of multiple factors with minimum fuzzy rule number requirements. The application of expert judgments and the convertible functions between possibility and probability help transform a subjective possibility measure into a quantitative probability scale capable of overcoming problems of insufficient data or complex systems. The proposed method can allow many experts to perform accident IQRA simultaneously also matches the practice of safety assessment conducted by multiple experts on construction sites. Thus it is possible to achieve improved objectivity of accident IQRA.

\section{REFERENCES}

1. Ashley, D. B. and Bonner, J. J., "Political risks in international construction," Journal of Construction Engineering and Management, ASCE, Vol. 113, No. 3, pp. 447-467 (1987).

2. Ayyub, B. M. and Haldar, A., "Decision in construction operation," Journal of Construction Engineering and Management, ASCE, Vol. 111, No. 4, pp. 343-357 (1985).

3. Bellamy, L. J. and Geyer, T. A. W., "Organizational, management and human factors in quantified risk assessment," HSE Contract Research Report, No. 33, Health and Safety Executive, London (1992).

4. Bellman, R., Adaptive Control Processes, Princeton University Press, Princeton (1966).

5. Cho, H. N., Choi, H. H., and Kim, Y. B., "A risk assessment methodology for incorporating uncertainties using fuzzy concepts," Reliability Engineering and System Safety, Vol. 78, pp. 173-183 (2002).

6. Choi, H. H., Cho, H. N., and Seo, J. W., "Risk assessment methodology for underground construction projects," Journal of Construction Engineering and Management, ASCE, Vol. 130, No. 2, pp. 258-272 (2004).

7. Choudhry, R. M. and Fang, D., "Why operatives engage in unsafe work behavior: Investigating factors on construction sites," Safety Science, Vol. 46, pp. 566-584 (2008).

8. Chun, M. H. and Ahn, K., "Assessment of the potential applicability of fuzzy set theory to accident progression event tree with phenomenological uncertainties," Reliability Engineering \& System Safety, Vol. 37, pp. 237-252, (1992).

9. Dağdeviren, M., Yüksel, I., and Kurt, M., “A fuzzy analytic network process (ANP) model to identify faulty behavior risk (FBR) in work system," Safety Science, Vol. 46, pp. 771-783 (2008).

10. Etienne, J., "Knowledge transfer in organisational reliability analysis: From post-accident studies to normal operations studies," Safety Science, Vol. 46, pp. 1420-1434 (2008).

11. Heinrich, H. W., Industrial Accident Prevention, McGraw-Hill, New York (1980).

12. Hinze, J., Construction Safety, Prentice-Hall, New Jersey (1997).

13. Howard, R. A. and Matheson, J. E., "Influence diagrams," The Principles and Applications of Decision Analysis, Vol. 2, pp. 719-726 (1984).
14. Huang, D., Chen, T., and Wang, M. J., “A fuzzy set approach for event tree analysis," Fuzzy Sets and Systems, Vol. 118, pp. 153-165 (2001).

15. Huwendiek, O. and Brockmann, W., "Function approximation with decomposed fuzzy systems," Fuzzy Sets and Systems, Vol. 101, pp. 273-286 (1999).

16. Laufer, A., "Construction safety: economics, information and management involvement," Construction Management and Economics, Vol. 5, pp. 73-90 (1987).

17. Lee, S. and Halpin, D. W., "Predictive tool for estimating accident risk," Journal of Construction Engineering and Management, ASCE, Vol. 129, No. 4, pp. 431-436 (2003).

18. Mamdani, E. H. and Assilian, S., "An experiment in linguistic synthesis with a fuzzy logic controller," International Journal of Man-Machine Studies, Vol. 7, No. 1, pp. 1-13 (1975).

19. Nishishima, S., Textbook for The Group Training Course in Industrial Safety and Health, Japan International Cooperation Agency, Tokyo (1989).

20. Onisawa, T., "An approach to human reliability in man-machine system using error possibility," Fuzzy Sets and Systems, Vol. 27, pp. 87-103 (1988).

21. Onisawa, T., "An application of fuzzy concepts to modeling of reliability analysis," Fuzzy Sets and Systems, Vol. 37, pp. 267-286 (1990).

22. Onisawa, T., "Subjective analysis of system reliability and its analyzer," Fuzzy Sets and Systems, Vol. 83, pp. 249-269 (1996).

23. Singer, D., "A fuzzy set approach to fault tree and reliability analysis," Fuzzy Sets and Systems, Vol. 34, pp. 145-155 (1990).

24. Sugeno, M., Industrial Applications of Fuzzy Control, Elsevier Science Publishing Co., New York (1985).

25. Suraji, A., Duff, R., and Peckitt, S. J., "Development of causal model of construction accident causation," Journal of Construction Engineering and Management, ASCE, Vol. 127, No. 4, pp. 337-344 (2001).

26. Suresh, P. V., Babar, A. K., and Raj, V. V., "Uncertainty in fault tree analysis: A fuzzy approach," Fuzzy Sets and Systems, Vol. 83, pp. 135-141 (1996).

27. Swain, A. D. and Gutemann, H. E., Handbook of Human Reliability Analysis with Emphasis on Nuclear Power Plant Applications, Sandia National Labs, NM (1983).

28. Tah, J. H. M. and Carr, V., "A proposal for construction project risk assessment using fuzzy logic," Construction Management and Economics, Vol. 18, pp. 491-500 (2000).

29. Tah, J. H. M. and Carr, V., "Knowledge-based approach to construction project risk management," Journal of Computing in Civil Engineering, ASCE, Vol. 15, No. 3, pp. 170-177 (2001).

30. Tanaka, H., Fan, L. T., Lai, F. S., and Toguchi, K., "Fault tree analysis by fuzzy probability," IEEE Transactions on Reliability, Vol. 32, No. 5, pp. 453-457 (1983).

31. Wang, L., "Universal approximation by hierarchical fuzzy systems," Fuzzy Sets and Systems, Vol. 93, pp. 223-230 (1998).

32. Weaver, D., "Symptoms of operational error," Professional Safety, Vol. 104, No. 2, pp. 39-42 (1971).

33. Wickens, C. D., Engineering Psychology and Human Performance, Harper Collins Publishers Inc., New York (1992).

34. Zabetakis, M., Accident Prevention, MSHA, Washington, (1975).

35. Zadah, L. A., "Fuzzy sets and systems," System Theory, Polytechnic Press, Brooklyn, NY, pp. 29-37 (1965).

36. Zadeh, L. A., "Fuzzy sets," Information and Control, Vol. 8, No. 3, pp. 338-353 (1965).

37. Zadeh, L. A., "Probability of measure of fuzzy events," Journal of Mathematical Analysis and Application, Vol. 23, pp. 421-427 (1968). 